\title{
A Comparative Study of Refusal Strategies Used by Iranians and Australians
}

\author{
Masoud Azizi Abarghoui \\ The Faculty of Humanities, the School of Foreign Languages, Islamic Azad University, Shahreza Branch, Iran \\ Email: Masoud_azizi@ymail.com
}

\begin{abstract}
This study investigated the differences between Iranian students-Persian speakers who are learning English as a foreign language-(20 male and 20 female) and the native participants (20 male and 20 female) Australian students majoring in different fields, refusal strategies. A Discourse Completion Task (DCT) was used to elicit the relevant data. The results showed that Iranian EFL students tend to use limited strategies for refusing their interlocutors' requests. Moreover, refusal patterns of natives are very different from those of non-natives, though they do share some similarities.
\end{abstract}

Index Terms—refusal strategies, Discourse Completion Task (DCT), EFL

\section{INTRODUCTION}

It is not strange for us to be in a situation where both the speaker and hearer fail to communicate. The barrier here is cultural awareness. They are from different cultures; thus, they have different frames of understanding. Among many of these terrible situations, refusing tends to cause tension.

Refusing is one of the significant issues in intercultural communication. The act of refusing is hazardous and possibly a producer of tension in intercultural interactions. As intercultural exchanges increase, as a result of travel, globalization, and international interactions, the potential for intercultural miscommunication through misinterpreted refusals also grows.

It is very important to remember that while native speakers often ignore phonological, syntactic, and lexical errors, they are less likely to overlook pragmatic errors. Such errors are typically interpreted by native speakers as arrogance, intolerance, rudeness, and so forth. Such studies in this regard can shed some light on these aspects of language.

This study is worthwhile in that it investigates the influence of interlocutors' social status and gender on the provided refusal strategies. While there are a lot of studies in the literature of refusals that have investigated the effect of interlocutors' social rank on their responses, very few have paid proper attention to the role of the speakers' gender in selecting refusal strategies.

Moreover, this study examines Iranian refusal strategies. The findings of this study may help Iranian to get acquaintance with the similarities and differences between Iranian and native English speakers' refusals and discover the cases of positive and negative cross-cultural pragmatic transfer. On the other hand, the cases which are culture-specific should be given more attention and practice.

\section{REVIEW OF THE RELATED LITERATURE}

Saying no is difficult for non-native speakers of a language. How one says 'no' is more important in many societies than the answer itself. Therefore, sending and receiving a message of 'no' is a task that needs special skill. The speaker must know when to use the appropriate form and its function depending on his and his interlocutor's cultural-linguistic values. Requests for favors involve doing activities that require some time or effort on the part of the addressee. Reasons, excuses or explanations can be considered as some kinds of attempts to persuade the interlocutor to change his/her mind.

\section{A. Speech Acts}

Refusing is a speech act. In order to actualize their purposes in communication, people seem to perform intended action while talking. Austin (1962) claims that there is a close connection between speech acts and language functions. Accomplishing communicative actions in everyday life requires using necessary words under appropriate circumstances. In other words, when we say something, we are simultaneously accomplishing a communicative action, that is, we are employing words to perform actions in real world context. For example, when we say," Could you please pass the book to me?" we wish to achieve the goal of having the intended addressee help us to obtain the book.

Austin's (1962) main contribution to speech act theory is the axiom that by saying something, we actually do something. A speech act is a unit of speaking and performs different functions in communication. Austin (1962) believes that a single speech act actually contains three separate but related speech acts: locutionary acts, illocutionary acts, and perlocutionary acts. Whenever a speaker produces an utterance, they perform a locutionary act. This is simply 
the act of producing a linguistically well-formed, and thus meaningful, expression. Moreover, we usually do not make utterances without having any purpose. Take the previous example ("Could you please pass the book to me?"). We not only utter that sentence but also ask the listener to give us a book. This kind of act via utterances which we produce with a communicative purpose in mind is generally known as illocutionary act. The illocutionary act is the function of the utterance that the speaker has in mind, i.e. the communicative purpose that is intended or achieved by the utterance. Another example is the statement "It's hot in here." This sentence can have the illocutionary force of a statement, an offer, an explanation, or a request. It might be uttered by someone who is experiencing heat in a crowded room to just comment on the weather. It can also be uttered by a person who intends to open the window so that everyone in the room can enjoy fresh air from outside.

Perlocutionary acts occur when we want a speech act to have an effect when we utter that statement. When saying" Could you please pass the book to me? "The speaker wishes the act of passing the book to be done: this is its perlocutionary force. The perlocutionary act refers to the hearer's recognition of and response to the illocutionary act (that is, the hearer may feel amused or annoyed, as a consequence of the speaker's utterance).Among the three acts, the perlocutionary act is regarded as the most important, as it is actually what the speaker wants to achieve through the action of uttering the sentence. Searle (1969) proposes a five-way classification of illocutionary acts, which includes:

1. Representatives: These speech acts constitute assertions carrying true or false values (e.g. statements).

2. Directives: In these speech acts, there is an effort on the part of the speaker to have the hearer do something (e.g. requests, advice).

3. Commissives: Speech acts of this kind create an obligation on the part of the speaker; that is; they commit the speaker to doing something (e.g. promises).

4. Expressives: These speech acts express an attitude or an inner state of the speaker which says nothing about the world (e.g. apologies, congratulations, compliments).

5. Declaratives: These are speech acts in which declarative statements are successfully performed and no psychological state is expressed (e.g. ex-communications).

These notions have contributed to the understanding of refusals of requests. They have played a noticeable role in forming the central and main concepts for the analysis of refusals in this research.

\section{B. Conversational Principles}

Several methods of communication have been used to keep the conversation developing gently. In any speech act, the conversants have to follow many principles, one of which is "cooperation". Conversation proceeds on the basis that participants are expected to deal respectfully with one another. In considering the suitability of participants' moves in conversation, Grice (1975) formulates a broad general principle, the Cooperative Principle stating some utterances such as: the conversational contribution should be made as is required, at the stage at which it occurs, by the accepted purpose or direction of the talk exchange in which it is engaged.

Grice (1975) enumerates the four following maxims, which characterize the cooperative principle:

1. Maxim of Quantity, or "to be brief", which means that you should make your contributions as informative as is required and no more. When we speak to someone, we feel obliged to give them enough details to enable them to understand us. At the same time, we should avoid giving too much information.

If something is said, there's a reason for it.

If something is left out, you're already supposed to know it.

2. Maxim of Quality, or "to be true", which requires you not to say what you believe to be false or for which you lack adequate evidence. Therefore, lying is an obvious violation of the cooperative principle.

If something known to be untrue is said, it is assumed to be intended to mislead, or to indicate ignorance.

Language can be made arbitrarily complex in this respect: consider irony or satire.

3. Maxim of Relation, or" to be relevant to the context and to what has been said previously", which requires people who usually change the subject unexpectedly to be considered impolite or uncooperative.

Of the many possible meanings of any language, you should select the one relevant to the shared goal.

4. Maxim of Manner, or "to be clear," which requires you to avoid ambiguity and obscurity. Speakers have to organize their utterances in an orderly manner, that is, to provide information in a way which can be assimilated by the listener.

Observing the four maxims helps sustain conversations. The speech act of refusing, like other speech acts, also requires the above-mentioned maxims to be considered in order to maintain a harmonious conversation. While people often utilize negotiation rather than direct refusal in their daily relationships, if the speaker is to convey the intended refusal without hurting the other's feelings, more subtle strategies may be required.

\section{The Concept of Face}

Formal restrictions on communication include not only ways of presenting "self" but also the ways in which we give face to others. Face can be considered as something that is emotionally expended and can be lost, maintained, or enhanced and must be always cared for in interaction (Brown and Levinson, 1987). In everyday discourse, we often submit to interlocutors by avoiding subtle and personal topics, we comfort our partners, and we avoid open disagreement. If we realize that our messages are not clear to the listeners, we highlight important items and mark 
background information. When we do not understand other persons, we give nonverbal or non-threatening feedback to the situation. By doing so, we are taking both our "face" and that of our partner into account.

According to Goffman (1967), there may be several reasons why people want to save their face. They may have become attached to the value on which this face has been built, they may be enjoying the results and the power that their face has created, or they may be taking care of higher social goals for which they will need this face. Goffman (1967) also defines face work as the way in which people maintain their face. This is done by presenting a firm image to others. Also, one can gain or lose face by improving or damaging this image. The more desirable the image, the more highly regard will be paid. People also have to make sure that while trying to keep their own face, they do not in any way damage the other's face.

\section{Face-threatening}

In daily communication, people may pose a threat to another individual's self-image, or create a" face- threatening act" (FTA). Some FTA's threaten negative face and some others threaten positive face. These acts prevent the freedom of action (negative face) and the wish that one's wants are desired by others (positive face) _by either the speaker, or the addressee, or both. The former includes directives such as commands, requests, advice, invitations, etc. The latter, on the other hand, includes criticisms, insults, disagreements, and corrections. Some speech acts threaten the hearer's face; some others threaten the speaker's face. Some scholars assert that requests potentially threaten the addressee's face because they may restrict the addressee's freedom to act according to his/her will. Refusals, on the other hand, may threaten the addressee's positive face because they may suggest that what he/she says is not favored by the speaker. However, there are still some other scholars who believe that some speech acts like refusals may threaten both interlocutors' faces. In other words, they are dual face-threatening acts. In an attempt to avoid FTAs; interlocutors use specific strategies to minimize the threat according to a reasonable estimation of the face risk to participants.

\section{E. Politeness Theory}

Early work on politeness by Goffman (1967) describes politeness as the amount of regard people show to their partners through avoidance or presentation of formal performances. While Leech (1983) sees it as forms of behavior aimed at creating and maintaining harmonious interaction. He also considers the politeness principle as part of the principles for interpersonal communications. He presents six maxims for the politeness principle:

1. Tact Maxim: Minimize cost to others. Maximize benefit to others.

2. Generosity Maxim: Minimize benefit to self. Maximize cost to self.

3. Approbation Maxim: Minimize dispraise of others. Maximize dispraise of self.

4. Modesty Maxim: Minimize praise of self. Maximize praise of others.

5. Agreement Maxim: Minimize disagreement between self and others. Maximize agreement between self and others.

6. Sympathy Maxim: Minimize antipathy between self and others. Maximize sympathy between self and others.

\section{F. Factors Affecting Directness and Indirectness in Human Interaction}

There are many socio-cultural factors affecting the directness-indirectness of utterances. Nguyen (1998) proposes twelve factors that, in his point of view, may affect the choice of directness and indirectness in communication:

1. Age: the old tend to be more indirect than the young.

2. Sex: females prefer indirect expression.

3. Residence: the rural population tends to use more indirectness than the urban.

4. Mood: while angry, people tend to use more indirectness.

5. Occupation: those who study social sciences tend to use more indirectness than those who study natural sciences.

6. Personality: the extroverted tend to use more directness than the introverted.

7. Topic: while referring to a sensitive topic, a taboo, people usually prefer indirectness.

8. Place: when at home, people tend to use more directness than when they are elsewhere.

9. Communicative environment/setting: when in an informal climate, people tend to express themselves in a direct way.

10. Social distance: those who have closer relations tend to talk in a more direct way.

11. Time pressure: when in a hurry, people are likely to use direct expressions.

12. Position: when in a superior position, people tend to use more directness to their inferiors.

These factors help to determine the strategies used when speakers perform the act of refusing.

\section{G. Pragmatic Transfer}

The influence of the first language (L1) in cross-cultural communication (pragmatic transfer) is often evident when native linguistic means of speech act performance are transferred to inter-language communication. Transfer occurs in two ways:

1. Negative transfer or "interference," where the two languages do not share the same language system, resulting in the production of errors.

2. Positive transfer or "facilitation," where the two languages share the same language system and the target form is correctly transferred. 
Pragmatic error or failure occurs where speech act strategies are inappropriately transferred from L1 to L2. Thus, cross- cultural studies focus on negative transfer because this is a source of misunderstanding and miscommunication.

Negative transfer is the result of overgeneralization, simplification, reduction of sociolinguistic or socio-pragmatic knowledge. The effect of negative transfer may be much more serious than an error at the syntactic or phonological level, because it can be interpreted as a representation of personality by the speaker. In other words, if a non-native speaker uses the target language correctly in terms of phonetics, vocabulary, and grammar, but manipulates it improperly in terms of social norms, a native interlocutor might think that he/she is not polite.

\section{H. Refusals Categorization}

Refusals are divided into two main groups, which is based on Beebe et al.'s (1990) classification and is as follows: direct refusals and indirect refusals. The direct refusals have very limited subdivisions in comparison to indirect ones. The direct refusals include non-performatives like "no" and performative verbs such as "I can't". The indirect refusals involve various types:

1. Statement of regret like "I'm sorry."

2. Wish like "I wish I could help you."

3. Excuse, reason, explanation like "I have an exam."

4. Statement of alternative.

5. Set condition for future or past acceptance like "If I had enough money"

6. Promise of future acceptance like "I'll do it next time."

7. Statement of principle "I never drink right after dinner."

8. Statement of philosophy like "One can't be too careful."

9. Attempt to dissuade interlocutor:

9-1. Threat or statement of negative consequences to the requester like "If I knew you would judge me like this I never did that"

9-2. Criticize the requester "It's a silly suggestion."

9-3. Guilt trip (waiter to customers who want to sit for a while: "I can't make a living off people who just order tea"

10. Acceptance functioning as a refusal:

10-1. Unspecific or indefinite reply "I don't know when I can give them to you"

10-2. Lack of enthusiasm "I'm not interested in diets"

11. Avoidance:

11-1. Non-verbal (silence, hesitation, doing nothing and physical departure)

11-2. Verbal (topic switch, joke, repetition of past request, postponement and hedge); An example for postponement can be "I'll think about it." There are also some adjuncts to the refusals as follows:

12. Statement of positive opinion like "That's a good idea"

13. Statement of empathy "I know you are in a bad situation"

14. Pause fillers like "well" and "uhm"

15. gratitude/appreciation like "Thank you."

\section{Sequence of Refusals}

The usual sequence in refusal strategy application is in three phases:

1. Pre-refusal strategies: preparing the addressee for an upcoming refusal;

2. Main refusal (Head Act): bearing the main refusal;

3. Post-refusal strategies: functioning as emphasizer, mitigator or concluder of the main refusal.

For example, a refusal sequence of someone to his friend's request for going to Movie theater together would be:

Uhm, I'd really like to (pre-refusal);

But I can't (main refusal);

I'm sorry. I 'm busy today (post- refusal).

The number of moves in a refusal depends on the type of refusal (whether it is direct or indirect).

Compare these two examples:

1. A: May I leave a message? B: No, you may not.

2. A: Have another sandwich. B: Thanks. Everything was so tasty, I Couldn't eat any more.

In the first example, the refusal involves only one move, which is a contradictory move, but in the second example the hearer refuses the proposition using more than one move. Naturally, indirect refusals take more moves to accomplish the refusals.

\section{J. Social Distance, Social Status, and Gender}

Social distance is one of the parameters that affect politeness behaviors. The notion of social distance refers to the attention which should be paid to the roles which are played by people respecting one another in a specific situation as well as how well they know each other, which means the level of intimacy between interlocutors. Some scholars claim that politeness increases with social distance. On the other hand, their ideas are opposed by some others who believe that there is very little consistency regarding speech behavior among strangers and intimates because of the relative pre- 
existing familiarity of their relationship, whereas the negotiation of relationships is more probable to happen among friends.

The role of social status in communication includes the ability to identify each other's social position. Some scholars claimed that people with high social status are more inclined to receive respectful and considerate behavior, including linguistic esteem and negative politeness. Thus those with lower social status are tending to avoid being rude and insulting those with higher status and show more respect to them.

Gender and speech behavior are also considered to be two interdependent, interrelated variables. In other words, speech behaviors depend on the gender relationship between interlocutors. Thus refusing people of either the same or the opposite gender requires different linguistic patterns.

In terms of pragmatics, requests and refusals are automatic sequences in the structure of the conversation which are called "adjacency pairs". "Adjacency pairs" is the term used for certain sequential speech moves that are closely connected . They can be depicted as automatic sequences including a first part and a second part produced by two successive speakers such that the second utterance is identified as related to the first as an expected follow-up. Having uttered the first part, the speaker immediately expects his/her conversational partner (interlocutor) to produce a second part of the same pair. The most common adjacency pairs are greeting-greeting, thanking-response, request refusal/acceptance, apology-acceptance, and question-answer. Managing adjacency pairs successfully is an important part of conversational competence. By producing an adjoining positioned second part, the second speaker can show that he/she can understand what the first speaker aims at and that he/she is ready to go along with that. The interlocutor can also assert their failure to understand, or disagreement. Otherwise, the first speaker him/herself may come to the conclusion that he/she misunderstands.

\section{K. Significance of This Issue}

The need for the scientific study of cross-cultural communication has been regarded as a main issue in the field of applied linguistics not only for the purposes of language learning and teaching, but also for enhancing cross-cultural understanding. Refusals are important because of their communicatively central place in every day communication. It is often difficult to reject requests. It is even harder to reject them in a foreign language without the risk of offending the interlocutor. This involves not only linguistic knowledge, but also pragmatic knowledge. One can have a wide range of vocabulary and a sound knowledge of grammar, but misunderstandings can still arise if they can not apply their pragmatic competence appropriately.

Based on the concepts discussed, the study on hand will put its emphasis on selected variables that control the way people deal with the act of refusing in their daily conversations. These include social distance (intimate, acquaintance, stranger); social status (low, high, equal); and gender (same gender, opposite gender). We begin working based on the literature on conversation and speech acts that these variables play main roles in the choice of strategies used by natives and Iranians.

\section{METHOD}

\section{A. Aims and Objectives of the Research}

As it has been mentioned before, there is a gap in our understanding of how Iranians apply the use of refusal patterns and how cultural influence affects their use of refusal speech acts in contact with native speakers of English. We investigate the strategies for refusal by the two. We also examine the influence of the interlocutor's social status, social distance and gender on refusal strategies by both groups.

\section{B. Participants}

As many as 40 Iranian students-Persian speakers who are learning English as a foreign language-(20 male and 20 female) participated in this study. They were selected through a speaking test. Moreover, the native participants were 40 (20 male and 20 female) Australian students majoring in different fields at the University of Queensland whose data were taken from a research done by Thi Minh Phuong in 2006.

\section{Instrumentation and Procedures}

The study uses a questionnaire in the form of Discourse Completion Task (DCT) for data collection. The questionnaire consists of 18 refusal situations that varied in terms of social status with three levels: low (L), high (H), and equal (E); social distance with three levels: intimate (I), acquaintance (A), and stranger (S); and gender relationship with two levels: same $(\mathrm{S})$ and opposite $(\mathrm{O})$. All of the questions in the questionnaire were coded, based on the combination of the three variables: social status, social distance, and gender.

All the questionnaires were administered in Islamic Azad University of Shiraz as was done in Phuong research in 2006.

\section{Data Analysis}


EFL students' refusal data were collected using a Discourse Completion Task (DCT). Using semantic formulae regarding the length and content of the responses, as units of analysis, they were compared with similar data elicited from native speakers of English responding in English.

\section{FINDINGS AND DisCUSSION}

The study at hand aimed to answer the following question:

To what extent do the refusal strategies used by these two groups differ?

\section{A. Prerequisite of the Study}

1. Interlocutors' status, social distance and gender have a great effect on refusals of request strategies used by native speakers and Iranian students.

2. Native speakers and Iranian students utilize different strategies for refusals of request.

\section{B. Results}

The differences of the frequency of each Speech Act Refusal (SAR) in each situation between natives and Iranian EFL students are shown in the following table.

TABLE 1:

FREQUENCY AND DIFFERENCES OF REFUSALS ACCORDING TO VARIOUS SITUATIONS

FREQUENCY AND DIFFERENCES OF REFUSALS ACCORDING TO VARIOUS SITUATIONS
\begin{tabular}{|l|l|l|l|}
\hline Situations & Natives & Iranian & Differences \\
\hline HIO & 70 & 44 & 26 \\
\hline LAS & 75 & 47 & 28 \\
\hline HIS & 28 & 44 & -16 \\
\hline ESS & 68 & 44 & 24 \\
\hline EIO & 85 & 47 & 38 \\
\hline HAS & 84 & 39 & 45 \\
\hline HSO & 90 & 43 & 47 \\
\hline EIS & 62 & 41 & 21 \\
\hline HSS & 79 & 45 & 34 \\
\hline EAO & 85 & 41 & 44 \\
\hline LSO & 46 & 48 & -2 \\
\hline EAS & 76 & 46 & 30 \\
\hline ESO & 74 & 47 & 27 \\
\hline LIO & 68 & 45 & 23 \\
\hline HAO & 81 & 41 & 40 \\
\hline LAO & 93 & 45 & 48 \\
\hline LSS & 88 & 39 & 49 \\
\hline LIS & 77 & 39 & 38 \\
\hline
\end{tabular}

As indicated by the data presented in the Table, natives outperformed Iranian EFL students in almost all situations except two.

Comparing the differences between the two groups shows that there are two striking features: natives and non-natives shared nearly the same number in some situations like LSO and the biggest difference between the groups was found in (LSS) with 88 SARs for natives and 39 SARs for non-natives.

\section{CONCLUSION}

We are now in the position to draw together the different patterns of refusal applied by the two groups based on the variables and SARs codes.

All in all, from the analysis of the data we can come to several broad conclusions: First, according to the results observed, Iranian EFL students tend to use limited strategies for refusing their interlocutors' requests. This can imply the fact that Iranian EFL learners have a limited pragmatic capacity to rely on when refusing their interlocutor's requests. Besides, based on the questionnaire data what individuals would do, refusal patterns of natives are very different from those of non-natives, though they do share some similarities. Parallel to cultural differences, lack of explicit teaching of refusal strategies in Iranian EFL classrooms can be considered as a major reason for their failure in utilizing appropriate strategies in some situations. Furthermore, English is a foreign language in Iran and there are only a few chances for students to put their language knowledge, especially the pragmatic knowledge, into practice outside the classroom context.

\section{REFERENCES}

[1] Austin, J.L. (1962). How to Do Things with Words. London: Oxford University Press

[2] Beebe, L.M., Takahashi, T., \& Uliss-Weltz, R.(1990). Pragmatic transfer in ESL refusals. In R.C. Scarcella, E.S. Andersen, \& S.D. Krashen (Ed.), Developing communicative competence in second language (pp. 55-73). New York: Newbury House.

[3] Brown, P., \& Levinson, S. C. (1987). Politeness: Some universals in language usage. Cambridge: Cambridge University Press. 
[4] Goffman, E. (1967). Interaction Ritual: Essays on Face-to-Face Behavior. New York: Pantheon Books.

[5] Grice, H.P. (1975). Logic and Conversation. In P. Cole and J.L. Morgan (eds.), Syntax and semantics 3:speech Acts. New York Academic Press.

[6] Leech, G.N. (1983). Principles of Pragmatics. London: Longman.

[7] Nguyen, T. P. (2006). Cross cultural pragmatics: Refusals of requests by Australian native speakers of English and Vietnamese learners of English. The University of Queensland.

[8] Searle, J.R. (1969). Speech acts- An essay in the philosophy of language. Cambridge: Cambridge University Press.

[9] Thi, M.P. (2006). Cross-cultural pragmatics: Refusals of Requests by Australian Native Speakers of English and Vietnamese Learners of English. Queensland: University of Queensland, Faculty of Arts, School of Languages and Comparative Cultural Studies.

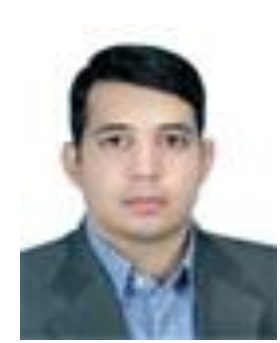

Masoud Azizi Abarghoui got his B.A in English language and literature from Sheikh Bahaee University (SHBU), Isfahan, Iran in 2007. Having participated in the M.A entrance exam, he was accepted at the Islamic Azad University, Shahreza branch, Iran to continue his studies in the field of teaching English as a foreign language (TEFL).

He is currently working as a lecturer at University of Applied Science and Technology (UAST), Abarkouh Branch, Iran. He has also worked as an English teacher for the Ministry of Education and Training in Yazd, and different local institutes including Iran Language Institute (ILI) since then. His areas of research interest are inter-language pragmatics, language skills instruction and assessment, and computer assisted language learning. 